\title{
PERANCANGAN APLIKASI INVENTORY CONTROL PT. KIMIA FARMA APOTEK
}

\author{
Alqomari Cahyo \\ Program Studi Informatika, Universitas Indraprasta PGRI \\ alqomari.cahyo@@unindra.ac.id
}

\begin{abstract}
Abstrak
PT. Kimia Farma Apotek yang bergerak di bidang layanan distribusi dan perdagangan produk kesehatan adalah salah satu perusahaan yang belum menggunakan sistem komputerisasi dalam hal pengedalian persediaan barang sehingga rentan akan kesalahan dan ketidakakuratan pendataan barang yang mengakibatkan sering terlupakan akan barang habis sebelum order ulang. Tujuan penelitian ini untuk merancang aplikasi inventory control dengan menggunakan bahasa pemrograman Java dan menggunakan metode research and development yang mana metode tersebut untuk menghasilkan produk tertentu dan menguji keefektifan produk tersebut. Hasil dari aplikasi yang di bangun dapat mempermudah karyawan dalam proses mengendalikan persediaan barang sehingga lebih efektif dan efisien
\end{abstract}

Kata Kunci : perancangan aplikasi, inventory control, research and development

\begin{abstract}
PT. Kimia Farma Apotek engaged in the distribution of and market in healthcare products is one of companies that has not used a computerized system in terms of controlling inventory so that it often makes errors in and inaccuracies of the goods collection, resulting in the running out of goods before reordering. The purpose of this research is to design an inventory control application using the Java programming language and applying research and development methods that can produce certain products and test the effectiveness of those products. The developed application can make it easier for employees to control inventory more effectively and efficiently.
\end{abstract}

Keywords : application design, inventory control, research and development

\section{PENDAHULUAN}

Dalam dunia bisnis, teknologi mampu membantu perkembangan bisnis karena teknologi dapat digunakan sebagai alat untuk memonitor kegiatan yang terjadi dalam bisnis diantaranya transaksi penjualan dan monitoring stok barang yang tersedia [1]. Persediaan merupakan barang dagangan yang di beli kemudian di simpan untuk selanjutnya dijual kembali dalam operasi karena dengan adanya persediaan stok barang dapat memudahkan jalannya proses produksiatau untuk memuaskan permintaan pelanggan [2].

Sistem pengendalian persediaan barang yang berjalan pada PT Kimia Farma Apotek saat ini masih menggunakan proses manual sehingga banyak kekurangan dalam kegiatan pencatatan transaksi keluar masuknya barang, stock barang, dan penyusunan laporan, hal ini dapat menyebabkan kinerja perusahaan menjadi terhambat dan belum mampu menunjang segala kebutuhan yang diinginkan perusahaan.

Penelitian ini bertujuan untuk merancang dan membuat sebuah aplikasi inventory control pada PT Kimia Farma Apotek yang awalnya masih menggunakan proses manual menjadi sebuah sistem yang cepat, tepat, efektif dan efisien. Aplikasi adalah suatu sistem yang dirancang dan disusun sedemikian rupa untuk menghasilkan informasi yang terpadu dengan menggunakan komputer sebagai sarana penunjang [3]. Perancangan merupakan proses pengembangan spesifikasi baru berdasarkan rekomendasi hasil analisis sistem [4]. 
Aplikasi yang dibuat dengan menggunakan bahasa pemrograman java. Java dikembangkan oleh perusahaan Sun Microsystem. Java menurut definisi dari Sun Microsystem adalah nama untuk sekumpulan teknologi untuk membuat dan menjalankan perangkat lunak pada komputer standalone ataupun pada lingkungan jaringan [5].

Manfaat yang di harapkan dari hasil penelitian ini adalah memberikan kemudahan serta dapat mempercepat, membuat efektif dan efisien pekerjaan karyawan yang ada di perusahaan tersebut.

\section{METODE PENELITIAN}

\section{Metode Penelitian}

Metode penelitian ini adalah penelitian Research and Development (R\&D), R\&D adalah metode penelitian yang digunakan untuk menghasilkan produk tertentu dan menguji keefektifan produk tersebut. Produk yang dikembangkan dalam penelitian ini berupa aplikasi inventory control pada PT. kimia Farma Apotek.

\section{Metode Pengembangan Sistem}

Metode pengembangan sistem yang digunakan penulis untuk mengembangkan sistem adalah metode waterfall yaitu salah satu metode pengembangan sistem informasi yang bersifat sistematis dan sekuensial, artinya setiap tahapan dalam metode ini dilakukan secara berurutan dan berkelanjutan. Metode waterfall memiliki tahapan-tahapan sebagai berikut [6], [7]:

\section{a. Analisa kebutuhan}

Pada tahap ini ada beberapa hal penting yang perlu dilakukan dalam pembuatan sistem inventory ini yaitu pengumpulan data untuk menggali informasi yang dibutuhkan untuk membuat aplikasi inventory control di PT. Kimia Farma Apotek. Adapun metode pengumpulan data yang penulis gunakan adalah sebagai berikut :
1) Wawancara

Melakukan komunikasi tanya jawab secara langsung dengan karyawan bahkan manajer tentang sistem inventory yang berjalan di PT. Kimia Farma Apotek.

2) Observasi

Dalam hal ini penulis langsung melihat atau mengadakan pengamatan ke bagian-bagian yang ada hubungannya dengan sistem informasi inventory control sekaligus pengumpulan dokumen-dokumen yang digunakan.

3) Studi Pustaka

Menggunakan beberapa buku sebagai referensi, untuk memperoleh penjelasan yang bersifat teori yang berhubungan dengan masalah yang diteliti.

4) Studi Literatur

Studi literatur digunakan untuk mengumpulkan data dari penelitian terdahulu, pembelajaran dari berbagai macam literatur dan dokumen seperti buku, jurnal dan teori-teori yang mendukung penelitian, tools yang akan digunakan dan data penunjang lainnya yang berkaitan dengan aplikasi inventory ini.

\section{b. Perancangan Sistem}

Pada tahapan ini Perancangan sistem bertujuan untuk merancang sistem yang akan dibuat agar dapat diimplementasikan dengan kebutuhan pengguna. Langkah-langkah yang dilakukan dalam perancangan sistem ini adalah :

1) Merancang database

2) Merancang antar muka

3) Melakukan validasi antarmuka

\section{c. Implementasi}

Pada tahap ini membuat aplikasi dengan pengkodean yang menggunakan bahasa java berdasarkan 
perancangan sistem yang telah di buat sebelumnya, yaitu pembuatan database, membuat antar muka dan memvalidasi antar muka ke bagian pergudangan.

\section{HASIL DAN PEMBAHASAN}

\section{Diagram Alir Data Sistem yang di Usulkan}

Pada diagram nol ini terdapat 5 entity yaitu: pimpinan, supplier, karyawan, petugas gudang, dan logistic support. Terdapat 5 proses yaitu : login, penerimaan, pembayaran, pengeluaran dan laporan. Adapun gambar diagram nol dapat di lihat pada gambar berikut :

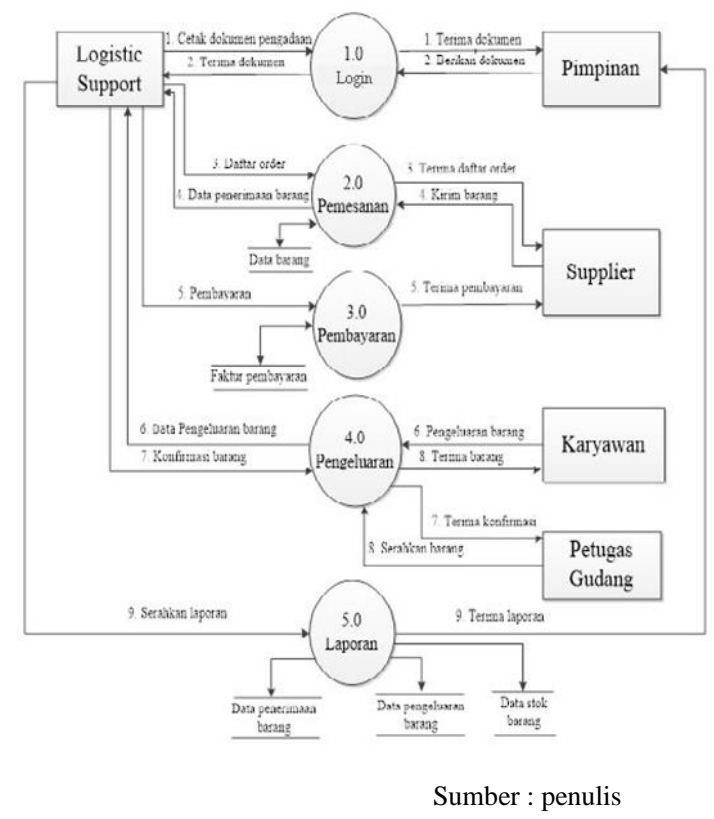

\section{Gambar 1. Diagram nol Sistem yang} Diusulkan

\section{Dekomposisi Fungsi}

Didalam dekomposisi fungsi ini terdapat menu akun, input, proses, dan output.

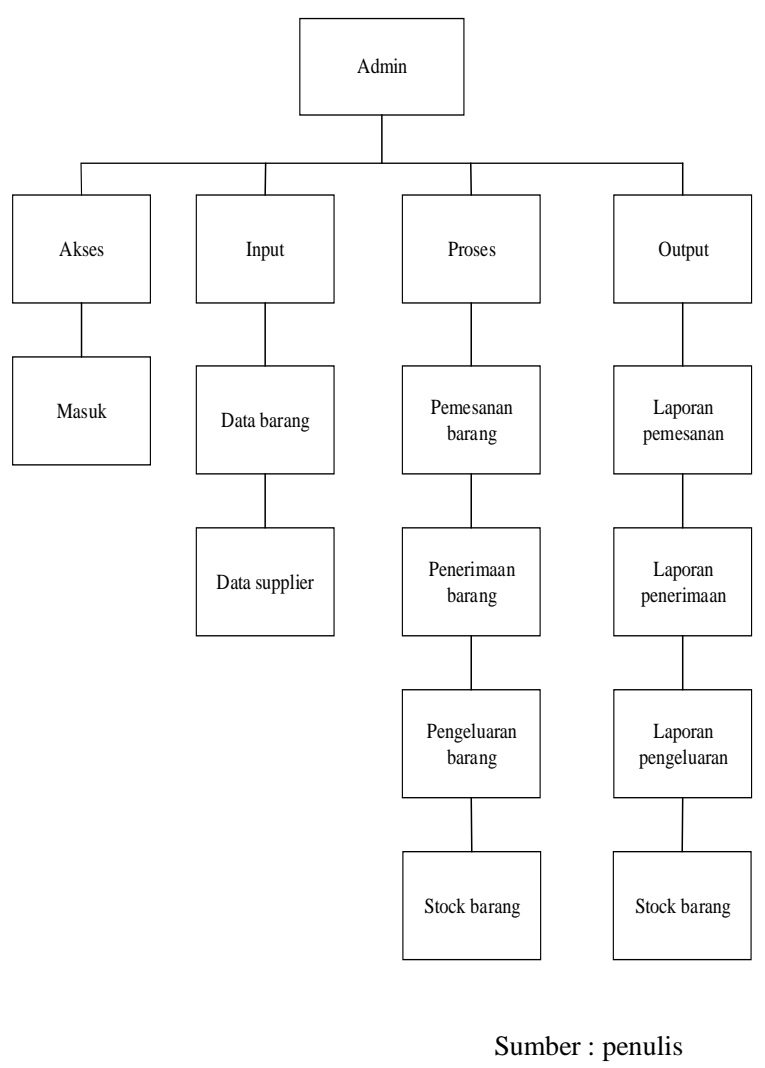

Gambar 2. Dekomposisi fungsi Aplikasi

\section{Tampilan Menu Login}

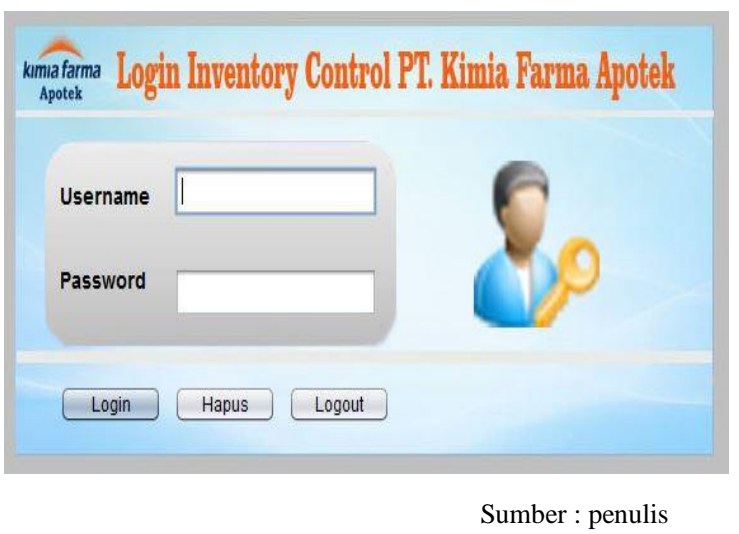

Gambar 3. Tampilan Menu Login

Form ini terdapat pada awal program, menu login digunakan sebagai kata kunci sebelum memasuki program utama. Agar tidak sembarangan orang dapat mengakses program ini. Sehingga dalam form ini kerahasiaannya tetap terjaga dengan baik. Apabila pengguna dapat memasukkan nama pengguna dan kata kunci dengan 
benar, maka akan tampil menu utama dan program siap untuk dijalankan

\section{Tampilan Menu Utama}

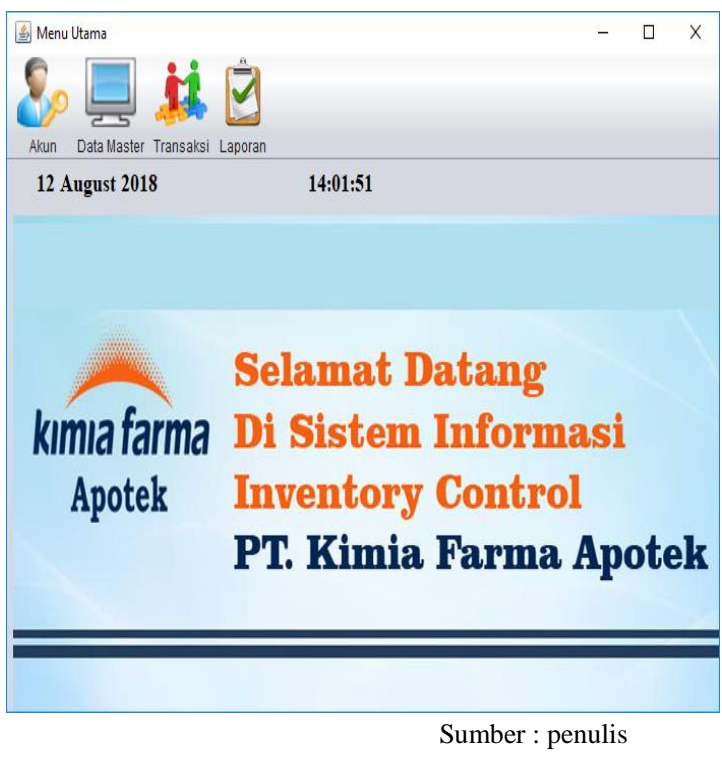

Gambar 4. Tampilan Menu Utama

Layar diatas menampilkan tampilan menu utama. Terdapat beberapa mеnu bar yang terdiri dari menu Akun sebagai akses untukmembuat hak akses disaat login, dan juga dapat keluar dari program. Menu Data Master untuk memasukkan data barang dan data supplier. Menu Transaksi sebagai menu untuk menginput data transaksi pemesanan barang, penerimaan barang, pengeluaran barang, stock barang. Menu Laporan untuk menampilkan laporanlaporan seperti pemesanan barang, penerimaan barang, pengeluaran barang, dan stock barang.

\section{Tampilan Menu Akun}

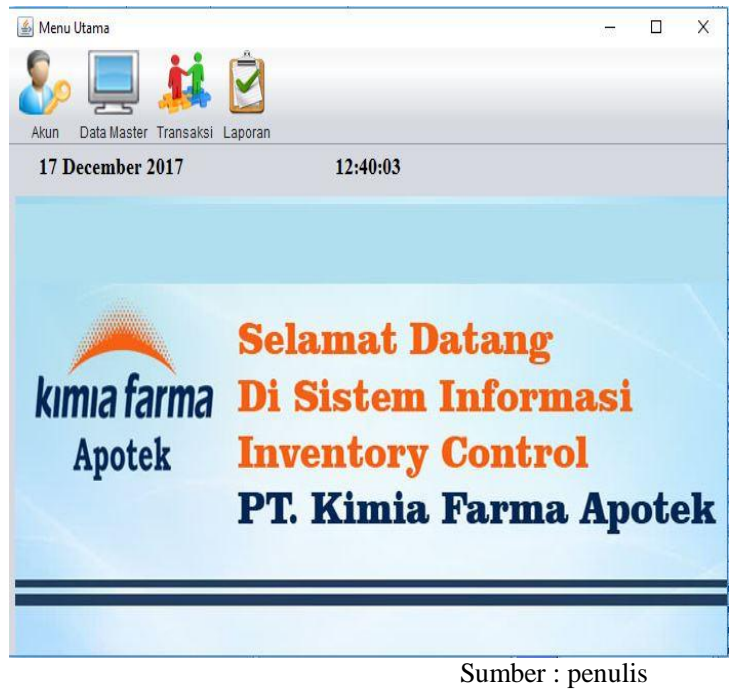

Gambar 5. Tampilan Menu Akun

Layar diatas merupakan tampilan menu Akun. Ketika user menekan (klik), sub menu Buat Akun maka akan memproses ke menu pembuatan akun guna untuk mendapatkan hak akses login. Selanjutnya jika user ingin keluar dari sistem klik Logout, yang nantinya kembali ke menu login.

\section{Tampilan Menu Data Master}

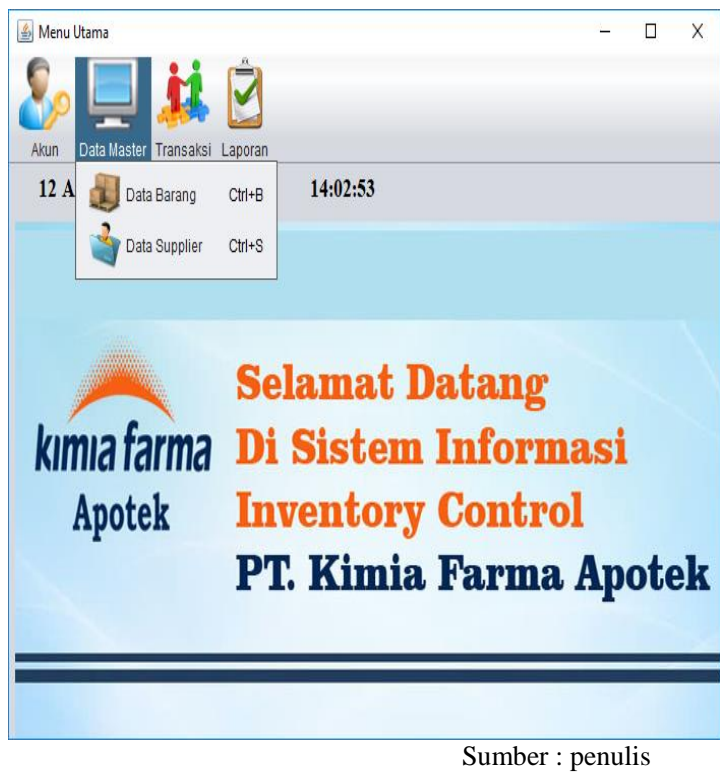

Gambar 6. Tampilan Menu Data Master

Layar diatas menampikan menu untuk memasukan data barang dan data supplier. 


\section{Tampilan Menu Transaksi}

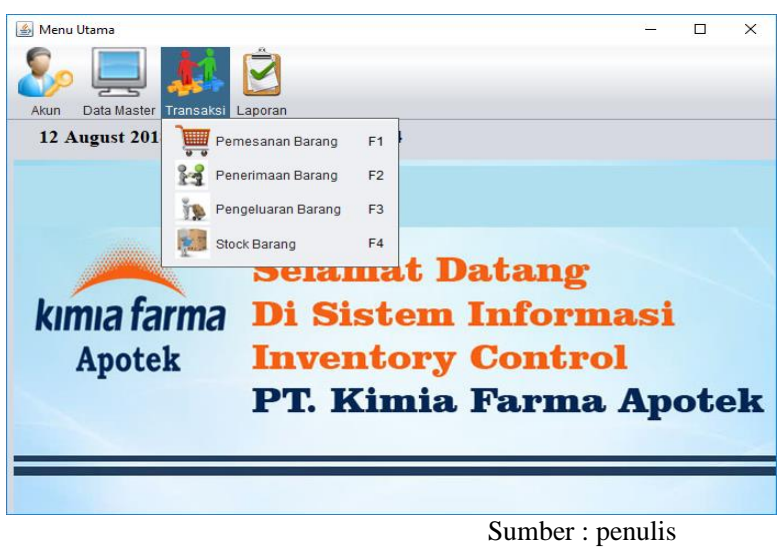

Gambar 7. Tampilan Menu Transaksi

Layar diatas menampilkan menu untuk memasukkan data pemesanan, penerimaan barang dari supplier, pengeluaran barang dari tiap-tiap unit kerja, dan stock barang.

\section{Tampilan Menu Laporan Pemesanan Barang}

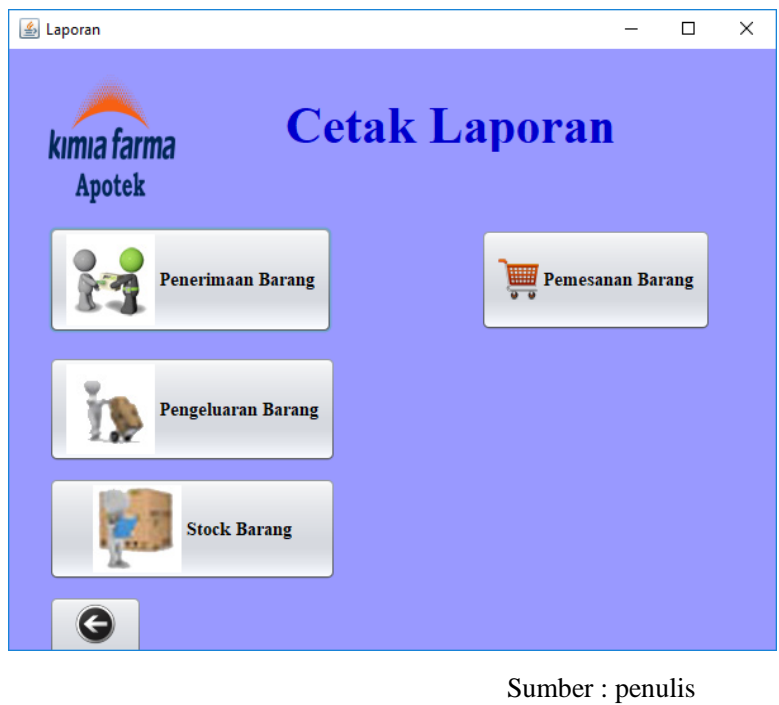

Gambar 8. Tampilan Menu Laporan Pemesanan Barang

Layar diatas menampilkan button untuk mencetak penerimaan barang, pengeluaran barang, stock barang dan pemesanan barang.
Tampilan Menu Laporan Penerimaan Barang

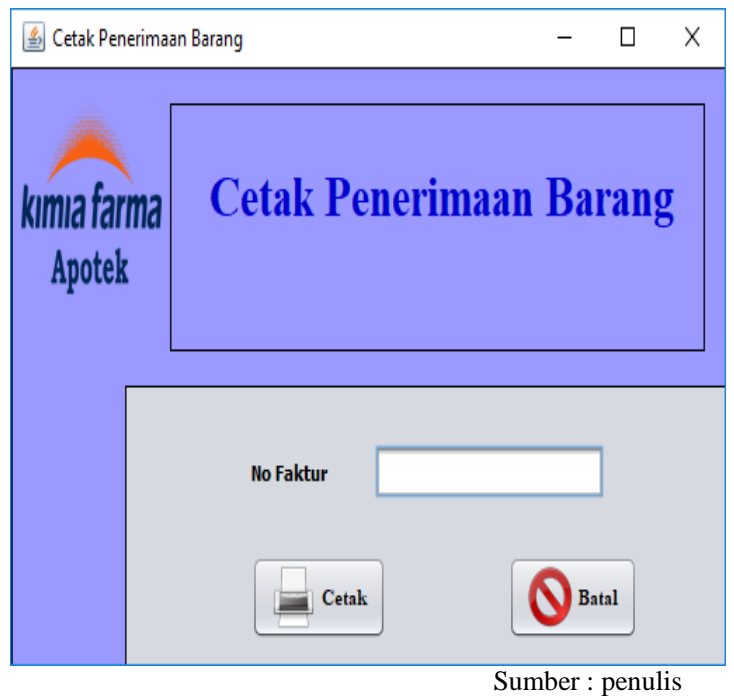

Gambar 9. Tampilan Menu Laporan Penerimaan Barang

Layar di atas menampilan button untuk mencetak penerimaan barang, dan terdapat juga button untuk membatalkannya.

\section{Tampilan Menu Laporan Pengeluaran Barang}

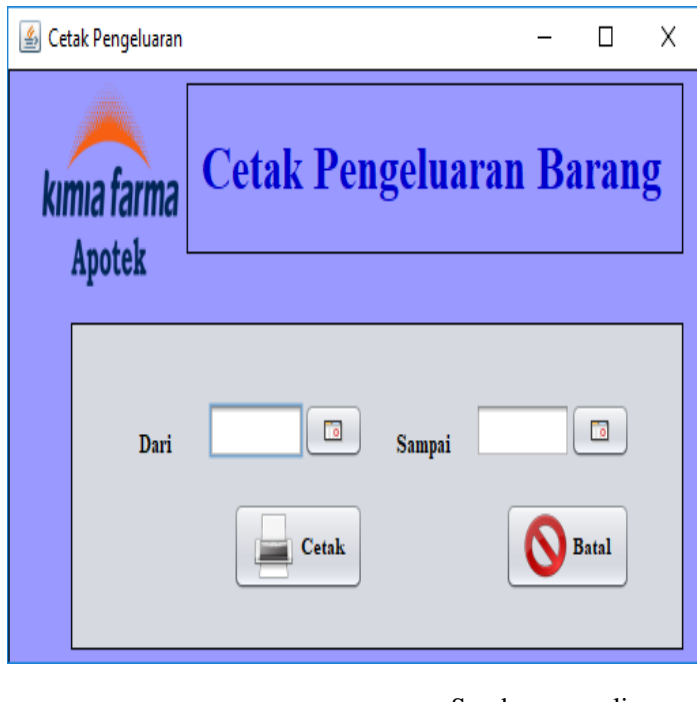

\section{Gambar 10. Tampilan Menu Laporan Pengeluaran Barang}

Layar di atas menampilkan button untuk mencetak pengeluaran barang, disitu juga terdapat pilihan tanggal pengeluaran barang yang mau dicetak. 


\section{Tampilan Format Masukan Input Data Barang}

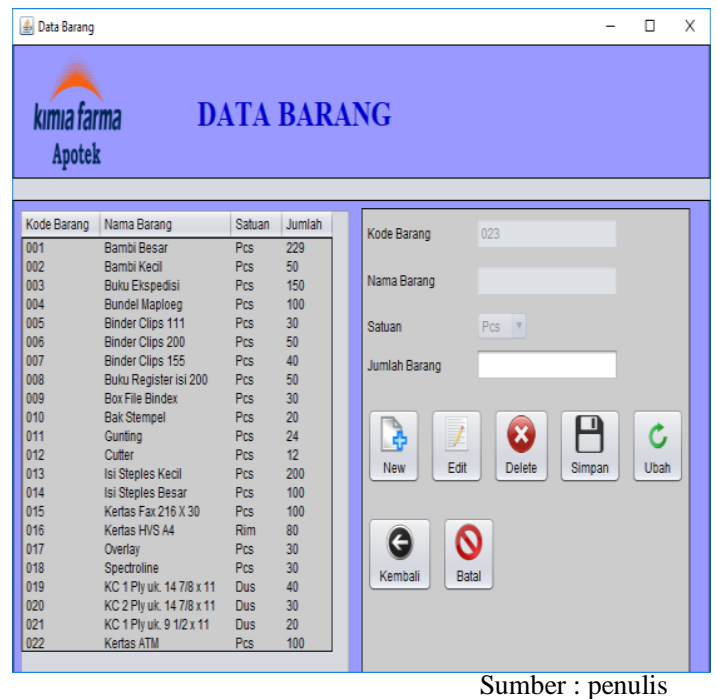

\section{Gambar 11. Tampilan Format Masukan Input Data Barang}

Layar diatas adalah tampilan form masukan input data barang terdapat table yang menampilkan list data barang yang ada, dan terdapat tombol button ner, edit, dellet, simpan, ubah, kembali dan batal dengan halaman form yang terdiri dari kode barang, nama barang, satuan dan jumlah barang.

\section{Tampilan Masukan Input Data Supplier}

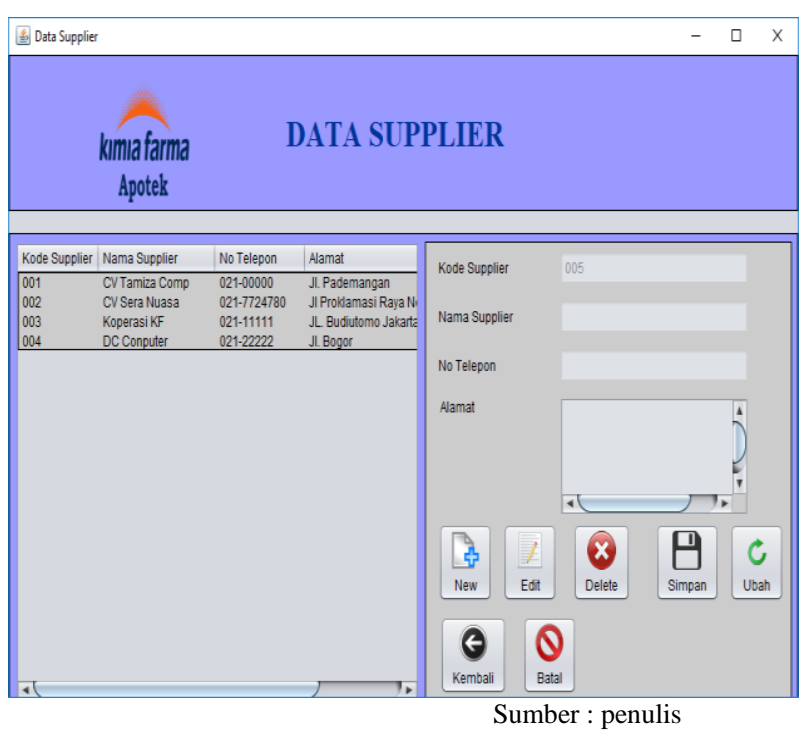

Gambar 12. Tampilan Masukan Input Data Supplier
Layar diatas adalah tampilan form data supplier terdapat table yang menampilkan list data supplier yang ada, dan terdapat tombol buttonnew, edit, delete, simpan, ubah, kembali dan batal dengan halaman form yang terdiri dari kode supplier, nama supplier, no telephone dan alamat.

\section{Tampilan Masukan Transaksi Pemesanan Barang}

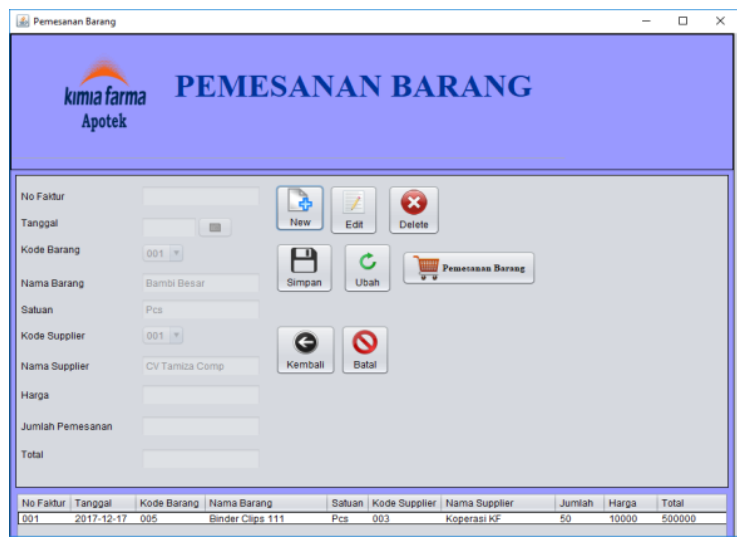

Sumber : penulis 2019

\section{Gambar 13. Tampilan Masukan Transaksi} Pemesanan Barang

Layar diatas adalah tampilan form data pemesanan barang terdapat table yang menampilkan list data pemesanan yang ada, dan terdapat tombol button new, edit, delete, simpan, ubah, kembali dan batal dengan halaman form yang terdiri dari no faktur, tangga, kode barang, satuan, kode supplier, nama supplier, harga, jumlah pemesanan dan total. 
Tampilan Input Transaksi Penerimaan Barang

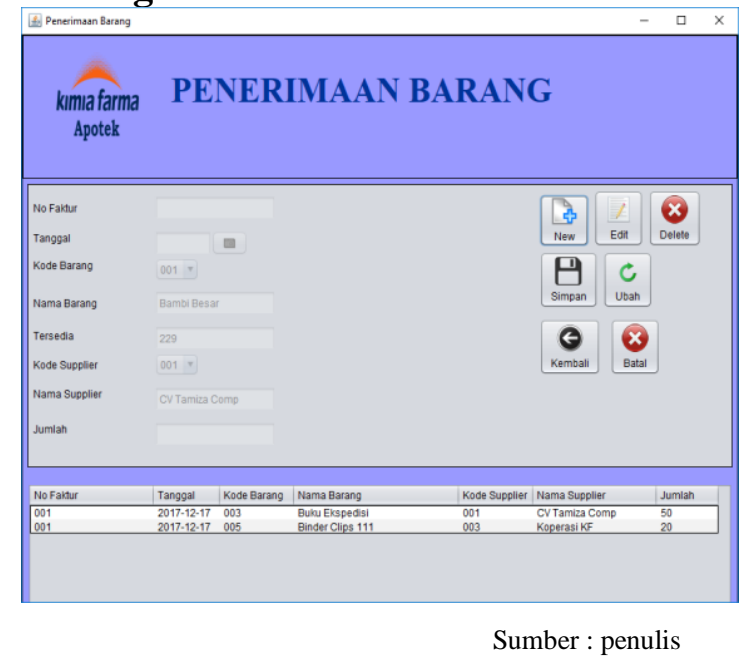

Gambar 14. Tampilan Input Transaksi Penerimaan Barang

Layar diatas adalah tampilan form penerimaan barang terdapat table yang menampilkan list data penerimaan barang yang ada, dan terdapat tombol button,new,edit, delete, simpan, ubah, kembali dan batal. dengan halaman form yang terdiri dari no faktur, tanggal, kode barang, nama barang, tersedia, kode supplier, nama supplier dan jumlah.

\section{Tampilan Input Transaksi Pengeluaran}

Barang

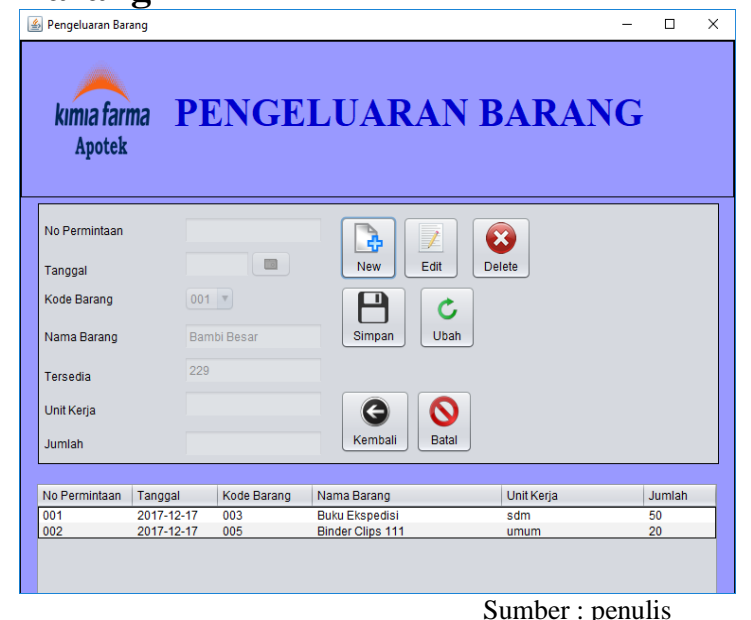

Gambar 15. Tampilan Input Transaksi Pengeluaran Barang

Layar diatas adalah tampilan form pengeluaran barang terdapat table yang menampilkan list data pengeluaran barang yang ada, dan terdapat tombol button new, edit, delete, simpan, ubah, kembali dan batal. dengan halaman form yang terdiri dari no penerimaan, tanggal, kode barang, nama barang, tersedia, unit kerja, dan jumlah.

\section{Tampilan Stock Barang}

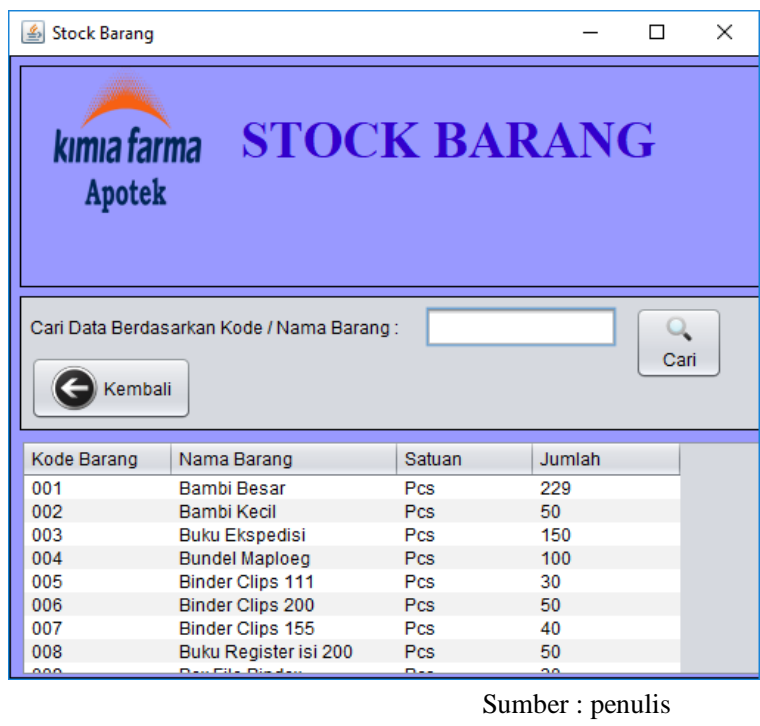

Gambar 16. Tampilan Stock Barang

Layar diatas adalah tampilan form stock barang terdapat table yang menampilkan list data stock barang yang ada, dan terdapat tombol pencarian nama barang yang akan dicari stocknya. Dengan halaman form yang terdiri dari kode barang, nama barang, satuan dan jumlah.

\section{Tampilan Dokumen Pemesanan Barang}

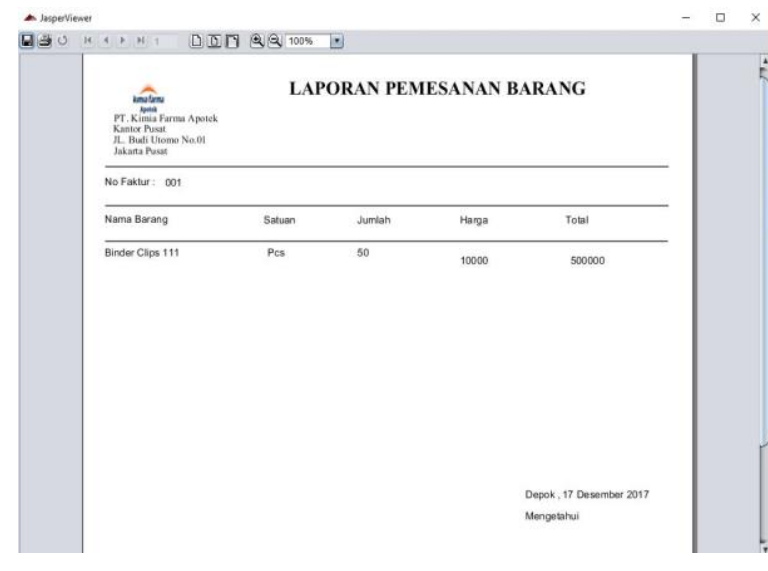

Sumber : penulis

Gambar 17. Tampilan Dokumen Pemesanan Barang 
Pada tampilan layar diatas merupakan tampilan keluaran laporan pemesanan barang, menampilkan data-data yang berisikan nama barang, satuan, jumlah dan harga total.

\section{Tampilan Laporan Penerimaan Barang}

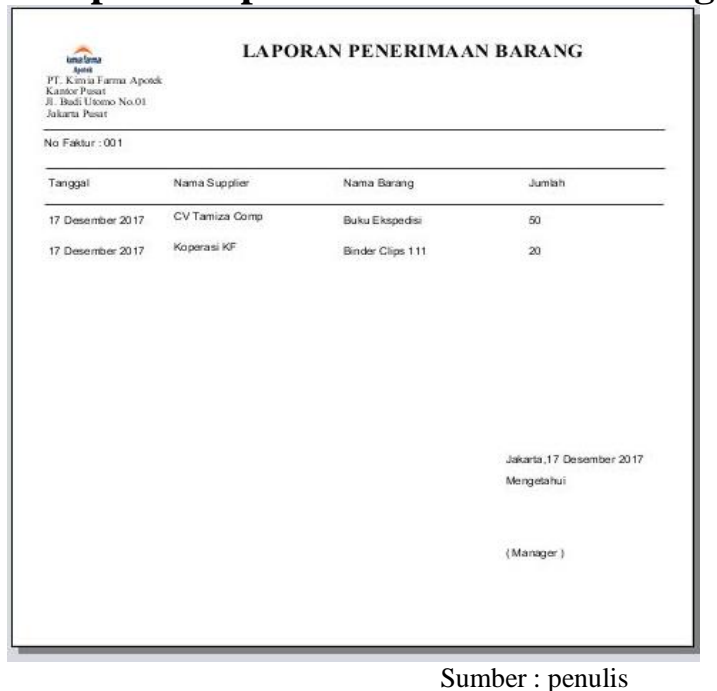

Gambar 18. Tampilan Laporan Penerimaan Barang

Pada tampilan layar diatas merupakan tampilan keluaran laporan penerimaan barang, menampilkan data-data yang berisikan tanggal, nama supplier, nama barang dan jumlah.

\section{Tampilan Laporan Pengeluaran Barang}

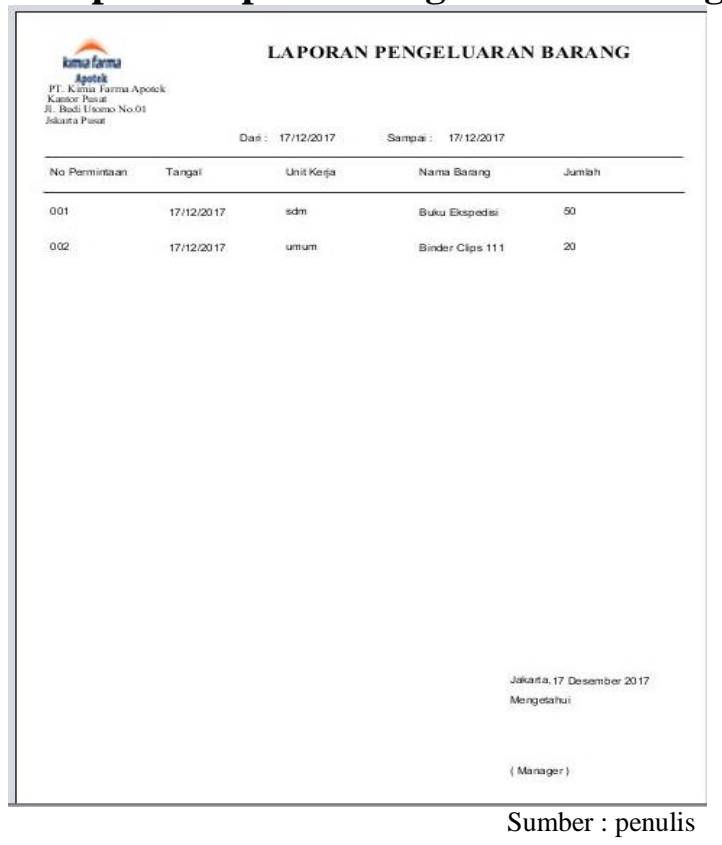

Gambar 19. Tampilan Laporan Pengeluaran Barang
Pada tampilan layar diatas merupakan tampilan keluaran laporan pengeluaran barang, menampilkan data-data yang berisikan tanggal, unit kerja, nama barang dan jumlah.

\section{Tampilan Laporan Stock Barang}

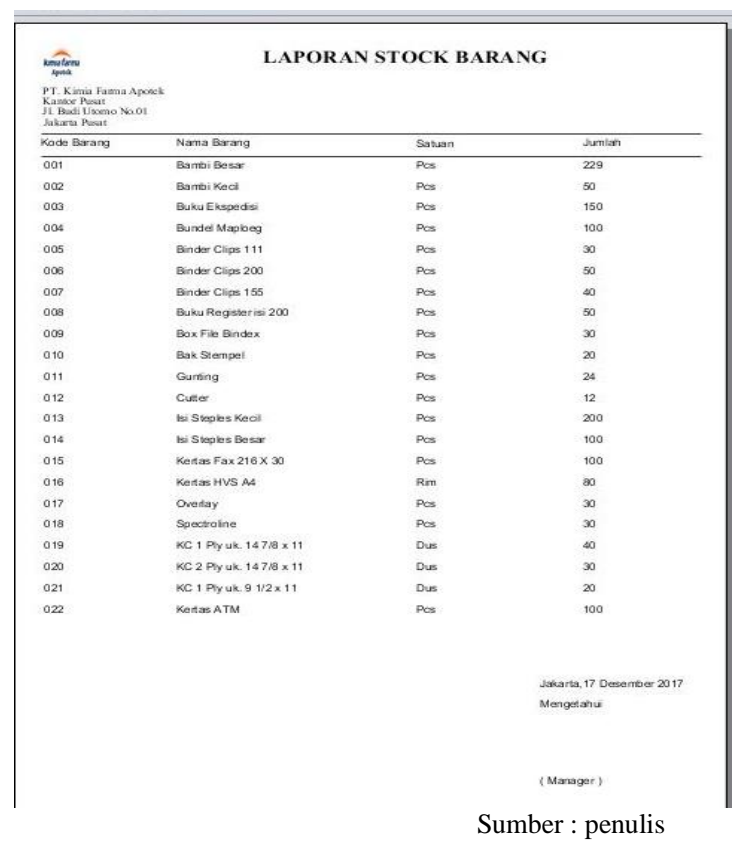

\section{Gambar 20. Tampilan Laporan Stock Barang}

Pada tampilan layar diatas merupakan tampilan keluaran laporan stock barang, menampilkan data-data yang berisikan nama barang, satuan dan jumlah.

\section{SIMPULAN}

Simpulan yang dapat diperoleh dari perancangan aplikasi Inventory Control di PT. Kimia Farma Apotek Berbasis Java, secara keseluruhan sistem telah dibuat sudah sesuai dengan yang diharapkan. Data yang telah diinputkan dapat diproses sesuai dengan fungsi dan menghasilkan sistem informasi yang dibutuhkan. Sistem dapat membantu dalam pembuatan PO (Purchase Order), penyimpan data supplier, pengecekan stock, pembuatan laporan penerimaan barang, pengeluaran barang, stock barang, pemesanan barang. Sistem ini memiliki kelemahan belum adanya proses retur. 


\section{DAFTAR PUSTAKA}

[1] Hendini, A. (2016). Pemodelan UML Sistem Informasi Monitoring Penjualan dan Stok Barang (Studi Kasus: Distro Zhezha Pontianak). Jurnal Khatulistiwa Informatika, IV(2), 107-116.

[2] Widya Tamodia. (2013). Evaluasi Penerapan Sistem Pengendalian Intern Untuk Persediaan Barang Dagangan Pada Pt. Laris Manis Utama Cabang Manado. International Law \& World Order, 1(3), 1-1. https://doi.org/10.1163/ILWO-IIIL46

[3] Jogiyanto, H.M., (2017), Analisa dan Desain Sistem Informasi: Pendekatan Terstruktur Teori dan Praktik Aplikasi Bisnis. Yogyakarta : Andi.
[4] Subhan. Mohamad, Analisa Perancangan Sistem, Jakarta: Lentera Ilmu Cendikia, 2012.

[5] Rosa. A.S., dan Shalahuddin. M. Rekayasa Perangkat Lunak Terstruktur dan Berorientasi Objek. Informatika : Bandung, 2013.

[6] Nasution, Ruslan Efendi. Implementation sms Gateway In The Development Web Base Information System Schedule Seminar Tesis. Lampung :Unila, 2012.

[7] Sukamto, R.A. dan Salahuddin, M., Rekayasa Perangkat Lunak, Bandung: Informatika Bandung, 2016. 